\title{
Qualidade de sementes de abóbora sob períodos de armazenamento e tratamento
}

\section{químico}

\author{
Pumpkin seed quality under storage and chemical treatment periods \\ Calidad de semilla de calabaza en periodos de almacenamiento y tratamiento químico
}

Recebido: 21/01/2022 | Revisado: 29/01/2022 | Aceito: 01/02/2022 | Publicado: 03/02/2022

\author{
Guilherme Rosario Rodrigues \\ ORCID: https://orcid.org/0000-0002-1943-4752 \\ Instituto Federal de Educação, Ciência e Tecnologia Goiano, Brasil \\ E-mail: guilherme-ifg.2013@hotmail.com \\ Luís Sérgio Rodrigues Vale \\ ORCID: https://orcid.org/0000-0002-6303-9063 \\ Instituto Federal de Educação, Ciência e Tecnologia Goiano, Brasil \\ E-mail: luis.sergio@ifgoiano.edu.br
}

\begin{abstract}
Resumo
As informações acerca de metodologias para avaliação de vigor de sementes de olerícolas são menos estudadas, inclusive de espécies de menor interesse comercial, como é o caso das mais diversas espécies de abóboras. Estudos que envolvam o armazenamento dessas sementes e efeitos do tratamento químico sob o seu vigor são necessários para maior conhecimento da manutenção da qualidade de sementes de abóbora. O objetivo desse trabalho foi avaliar a qualidade de sementes de "Abóbora de Porco" sob diferentes períodos de armazenamento e tratamento químico. O experimento foi realizado no laboratório de análise de sementes do Instituto Federal Goiano - Campus Ceres. Os tratamentos foram: com e sem tratamento químico e cinco períodos de armazenamento (0, 30, 60, 90 e 120 dias). Foram realizadas as seguintes análises: pureza física, massa de mil sementes, grau de umidade, condutividade elétrica, germinação, massa seca de plântulas, emergência em campo e índice de velocidade de emergência. Os dados foram submetidos ao teste de Tukey (5\%) pelo Sisvar e a análise de regressão. Observou-se que as sementes armazenadas perderam umidade e tiveram aumento da condutividade elétrica em função do armazenamento. Não houve diferença significativa na germinação de sementes com a aplicação ou não de tratamento químico nos períodos estudados. A emergência de plântulas com tratamento de sementes foi maior até os 90 dias.
\end{abstract}

Palavras-chave: Cucurbita pepo L.; Emergência; Germinação; Vigor.

\begin{abstract}
The informations about methodologies for evaluating the vigor of vegetable seeds is less studied, including species of less commercial interest, such as the most diverse species of pumpkins. Studies involving the storage of these seeds and the effects of chemical treatment on their vigor are necessary for a better understanding of the maintenance of the quality of pumpkin seeds. The objective of this work was to evaluate the quality of "Pumpkin of Pig" seeds under different periods of storage and chemical treatment. The experiment was carried out in the seed analysis laboratory of Instituto Federal Goiano - Campus Ceres. The treatments were: with and without chemical treatment and five storage periods $(0,30,60,90$ and 120 days). The following analyzes were carried out: physical purity, mass of a thousand seeds, moisture content, electrical conductivity, germination, dry mass of germinated seedlings, field emergence and emergence speed index. Data were submitted to Tukey's test (5\%) by Sisvar and regression analysis. It was observed that the stored seeds lost moisture and had an increase in electrical conductivity as a function of storage. There was no significant difference in seed germination with or without the application of chemical treatment in the studied periods. The emergence of seedlings with seed treatment was higher up to 90 days.
\end{abstract}

Keywords: Cucurbita pepo L.; Emergency; Germination; Vigor.

\section{Resumen}

La información sobre metodologías para evaluar el vigor de semillas de hortalizas está menos estudiada, incluyendo especies de menor interés comercial, como las más diversas especies de calabazas. Los estudios que involucran el almacenamiento de estas semillas y los efectos del tratamiento químico en su vigor son necesarios para una mejor comprensión del mantenimiento de la calidad de las semillas de calabaza. El objetivo de este trabajo fue evaluar la calidad de semillas de "Calabaza de Cerdo" bajo diferentes periodos de almacenamiento y tratamiento químico. El experimento se realizó en el laboratorio de análisis de semillas del Instituto Federal Goiano - Campus Ceres. Los tratamientos fueron: con y sin tratamiento químico y cinco periodos de almacenamiento $(0,30,60,90$ y 120 días). Se realizaron los siguientes análisis: pureza física, masa de mil semillas, contenido de humedad, conductividad eléctrica, germinación, masa seca de plántulas germinadas, emergencia en campo e índice de velocidad de emergencia. Los 
datos fueron sometidos a la prueba de Tukey (5\%) por Sisvar y análisis de regresión. Se observó que las semillas almacenadas perdieron humedad y tuvieron un aumento en la conductividad eléctrica en función del almacenamiento. No hubo diferencia significativa en la germinación de semillas con o sin la aplicación de tratamiento químico en los periodos estudiados. La emergencia de plántulas con tratamiento de semillas fue mayor hasta los 90 días.

Keywords: Cucurbita pepo L.; Emergencia; Germinación; Fuerza.

\section{Introdução}

A abóbora é uma planta herbácea de crescimento geralmente rasteiro ou trepador. Se caracteriza por ser uma cultura de ciclo anual, com crescimento "indeterminado" onde as ramas alongam-se até seis metros, com grande variação em seus frutos em relação à forma, coloração interna e externa (Sales et al., 2015). A abóbora compreende um total de 27 espécies (Cucurbita spp.), e pertence à família das Cucurbitaceae (CPRA, 2014). A abóbora de porco (Cucurbita pepo L.) é uma olerícola que se adapta aos diferentes tipos de clima e solo, por esse motivo é cultivada em todas as regiões do Brasil (Coelho et al., 2020).

A utilização de sementes de boa qualidade é fundamental para o estabelecimento adequado de uma lavoura (Araújo et al. 2011). A qualidade da semente é caracterizada pelos atributos genético, físico, sanitário e fisiológico, sendo fundamental no processo de produção de qualquer espécie vegetal multiplicada por sementes (Gomes Junior \& Sá, 2010).

As metodologias para avaliação do vigor de sementes são em menor escala na maioria das culturas olerícolas, inclusive na cultura da abóbora, o que é justificado pela maior concentração de interesse no estudo de sementes das grandes culturas (Torres et al., 2014). Para análise mais precisas da qualidade de sementes, faz-se necessário complementar as informações fornecidas pelo teste de germinação, com testes de vigor, possibilitando, assim, selecionar os melhores lotes para comercialização e semeadura (Araújo et al., 2011).

Para Carvalho e Nakagawa (2012), frutos recém-colhidos possuem um teor de água alto nas sementes, sendo assim, inadequados para o armazenamento com segurança e necessitando, portanto, de secagem. Essa operação é necessária, pois o alto teor de água das sementes é uma das principais causas da perda de sementes no armazenamento, além de afetar as operações de beneficiamento, dificultando muitas vezes o manejo reduzindo assim a eficiência das máquinas utilizadas nos processos de beneficiamento (Costa Júnior et al., 2021).

$\mathrm{O}$ armazenamento prolongado das sementes geralmente implica em uma queda em seu vigor. Essa redução do vigor é causada pela peroxidação lipídica das reservas no período de armazenamento (Medeiros et al., 2013; Maciel et al., 2015). A qualidade das sementes não é melhorada pelo armazenamento adequado, mas sim, preservada com o mínimo de deterioração possível, visando manter o vigor e o poder germinativo pelo maior período possível (Goldfarb \& Queiroga, 2013; Zucareli et al., 2015).

No armazenamento outro problema recorrente são as pragas e patógenos que podem causar danos às sementes armazenadas, ainda mais sob elevada umidade. Neste sentido, o tratamento de sementes ajuda a controlar os avanços das doenças e as infestações de insetos (Freitas, 2011). O tratamento de sementes objetiva, basicamente, conferir proteção contra insetos-pragas às sementes e às plântulas delas originadas, proporcionando a manutenção da qualidade sanitária da semente (Tonin et al., 2014).

Desta forma, o tratamento químico além de assegurar a sanidade do lote, pode ajudar no potencial genético que este carrega, de modo que a escolha do produto e os testes de controle devem evitar riscos de danos ao potencial fisiológico das sementes (Nunes, 2016). O objetivo desse trabalho foi avaliar a qualidade de sementes de "Abóbora de Porco" sob diferentes períodos de armazenamento e tratamento químico. 


\section{Metodologia}

O experimento foi realizado no laboratório de análise de sementes (LAS) do Instituto Federal Goiano - Campus Ceres, no período de junho a outubro de 2021. As sementes de "Abóbora de Porco" (Cucurbita pepo L.), foram adquiridas de um produtor rural de Teresópolis, GO. As sementes haviam sido extraídas de forma manual cerca de 90 dias antes de serem adquiridas, passaram por um processo de secagem natural por 72 horas em uma bancada à sombra e depois, foram armazenadas em garrafa pet em condições de ambiente natural.

No LAS uma parte das sementes foi colocada em sacos plásticos onde aplicou-se o tratamento químico. Para o tratamento químico foi utilizado o produto comercial Standak ${ }^{\circledR}$ Top UBS na dose de $1 \mathrm{~mL} \mathrm{~kg}^{-1}$, que atua como fungicida e inseticida, conferindo ação protetora (Piraclostrobina), sistêmica (Tiofanato Metílico) e de contato e ingestão (Fipronil). Após a secagem e tratamento, as sementes permaneceram por 24 horas de repouso antes de serem submetidas às análises e ao armazenamento.

As sementes foram armazenadas em sacos de papel pipoca amanteigado em um refrigerador $\left(2 \mathrm{a} 4^{\circ} \mathrm{C}\right)$ no laboratório. Foi utilizado o delineamento inteiramente casualizado (DIC), com 10 tratamentos $(2$ x 5) e quatro repetições. Os tratamentos foram: dois tipos de tratamentos químico de sementes (com e sem) e cinco períodos de armazenamento (0, 30, 60, 90 e 120 dias).

As sementes foram submetidas em laboratório às seguintes análises: Pureza Física de sementes (PS) - Antes de aplicar os tratamentos de sementes e o os períodos de armazenamento foi utilizada a metodologia de acordo com Brasil (2009), para avaliação da pureza física de sementes. Foi utilizada uma amostra de 700 gramas de sementes que foram pesadas e separadas de todo o material inerte. Assim, foi obtida a porcentagem de sementes puras.

O Grau de umidade (GU) foi realizado com as sementes armazenadas por diferentes períodos e não tratadas quimicamente. Foram utilizadas quatro repetições de 25 sementes, submetidas a estufa de secagem a $105{ }^{\circ} \mathrm{C}$ por $24 \mathrm{~h}$ e, posteriormente, as amostras foram pesadas em balança analítica conforme Brasil (2009). A análise do grau de umidade foi realizada após a secagem em estufa.

A Massa de Mil Sementes (MMS) foi realizada antes de aplicar o tratamento químico de sementes e os períodos de armazenamento. Utilizou-se oito repetições de 100 sementes provenientes da porção sementes puras que foram pesadas e feita a extrapolação através da fórmula:

$$
\text { Massa de mil sementes }=\frac{\text { Peso da amostra }}{\mathrm{N}^{\circ} \text { total de sementes }} \times 1000
$$

A Condutividade Elétrica de Sementes (CS) foi realizada com as sementes armazenadas nos diferentes períodos e não tratadas quimicamente. Foram utilizadas quatro repetições de 25 sementes. Essas sementes foram pesadas em balança de precisão e colocadas em recipientes de plástico $(200 \mathrm{~mL})$, com $75 \mathrm{~mL}$ de água deionizada. Após, os recipientes com as sementes e água foram colocados na câmara de germinação do tipo B.O.D (Biochemical Oxygen Demand), com a temperatura de $25^{\circ} \mathrm{C}$ por 24 horas. Após esse período foi realizada a leitura com auxílio de um condutivímetro de bancada. Os resultados foram expressos em $\mu \mathrm{S} \mathrm{cm}^{-1} \mathrm{~g}^{-1}$ (Andrade et al., 1999).

Para o Teste de Germinação (TG) foi utilizado o método do rolo de papel conforme Brasil (2009). Foi utilizado papel germitest umedecido com água destilada com a quantidade equivalente a 2,5 vezes o peso seco do papel. Foram utilizadas quatro repetições de 50 sementes para cada tratamento que foram colocadas em um germinador do tipo B.O.D, com a temperatura de $25^{\circ} \mathrm{C}$. A primeira contagem das plântulas normais foi realizada aos 4 dias após a montagem do teste e a última aos 8 dias (Brasil, 2009). 
Para a Massa Seca de Plântulas do TG (MSG), as plântulas passaram por um processo de secagem em estufa com ventilação forçada de ar a $70{ }^{\circ} \mathrm{C}$ por 48 horas. Após, as amostras foram pesadas em balança de precisão e foi calculada a massa seca média por plântula.

A Emergência em Campo (EC) foi realizada em canteiros com areia lavada em casa de vegetação, com quatro repetições de 50 sementes. No $5^{\circ}$ e $11^{\circ}$ dias após a semeadura foi realizada a contagem de plântulas que emergiram e os resultados expressos em porcentagem (Brasil, 2009).

O Índice de Velocidade de Emergência (IVE) foi realizado em conjunto com o teste de emergência em areia com contagens periódicas de dois em dois dias a partir do $5^{\circ}$ dia até o $11^{\circ}$ dia (contagem final). Após o término do teste foi calculado o índice de velocidade de emergência pela fórmula proposta por Maguire (1962):

$\mathrm{IVE}=\frac{\mathrm{E} 1+\mathrm{E} 2+\ldots \mathrm{Ei}}{\mathrm{T} 1+\mathrm{T} 2+\ldots \mathrm{Ti}}$

Onde:

IVE é índice de velocidade de emergência;

E1 até Ei é o número de emergência ocorrida a cada dia;

T1 até Ti é o tempo (dias).

Os dados foram processados estatisticamente e submetidos à análise de variância (ANOVA) na probabilidade de 5\% pelo teste de Tukey. $\mathrm{O}$ tratamento do período de armazenamento das sementes foi submetido à análise de regressão. Os dados foram submetidos ao programa computacional Sisvar 5.6 para as análises estatísticas.

\section{Resultados e Discussão}

A amostra de sementes de abóbora de porco do experimento apresentou pureza física de 99,21\% (Tabela 1). O resultado está de acordo com os padrões aceitáveis para sementes de abóbora comerciais básicas e certificadas, em que se estabelece uma pureza física de 98\% (Brasil, 2019). Conforme Melo et al. (2016), uma maior pureza física em um lote de sementes é um fator primordial para garantir uma menor ocorrência de vários incidentes no lote, que possam torná-las impróprias para a semeadura. Como a extração das sementes foi manual, praticamente não houve material inerte ou sementes de outras espécies.

Tabela 1. Pureza Física e Massa de Mil Sementes de "Abóbora de Porco". Ceres, GO, 2021.

\begin{tabular}{cc}
\hline Análises & Resultados \\
\hline Pureza Física & $99,21 \%$ \\
Massa de Mil de Sementes & $108,32 \mathrm{~g}$ \\
\hline
\end{tabular}

Fonte: Arquivo Pessoal (2022).

Em relação à massa de mil sementes obteve-se resultado de 108,32 g (Tabela 1). O resultado é superior ao descrito na literatura para diferentes espécies de abóboras (Cardoso, 2005; Silva \& Lopes, 2012; Freitas et al., 2014). Sementes que apresentam maior massa podem apresentar um maior vigor uma vez que ocorre um maior acúmulo de nutrientes no desenvolvimento, que podem resultar em embriões com melhor formação e com mais reserva, permitindo melhores condições quando submetidas a campo (Wagner Júnior et al., 2011; Cruz et al., 2020).

Em relação ao grau de umidade das sementes observou-se um comportamento linear decrescente (Figura 1). Com o aumento do período de armazenamento ocorreu redução no grau de umidade das sementes, sendo a menor umidade $(10,2 \%)$ observada no período final de avaliação (120 dias). De modo geral, o grau de umidade das sementes está de acordo com os padrões exigidos em função dos diferentes períodos de armazenamento. Marcos Filho (2015) descreve que em geral as 
sementes devem ser mantidas com grau de umidade variando entre 10 e $12 \%$, de forma a permitir um armazenamento seguro, possibilitando que haja a manutenção de sua qualidade fisiológica e o vigor. Para Nascimento et al. (2008), as sementes de abóbora podem ser armazenadas com umidade de até $6 \%$ sem que haja perdas de qualidade e vigor. Quando a pressão de vapor da semente é maior que a do ar circundante, ocorre o fenômeno de dessorção, ou seja, ocorre a transferência de vapor de água para o ar, reduzindo, desta forma, a umidade das sementes (Silva et al., 1995).

O grau de umidade das sementes é um fator determinante em seu armazenamento, já que conforme Queiroga et al. (2009), quanto menor a quantidade de água presente nas sementes no período de armazenamento, maior será a longevidade do lote de sementes, desde que se respeite o limite ideal de cada espécie.

Figura 1. Grau de umidade de sementes de "Abóbora de Porco" sob diferentes períodos de armazenamento.

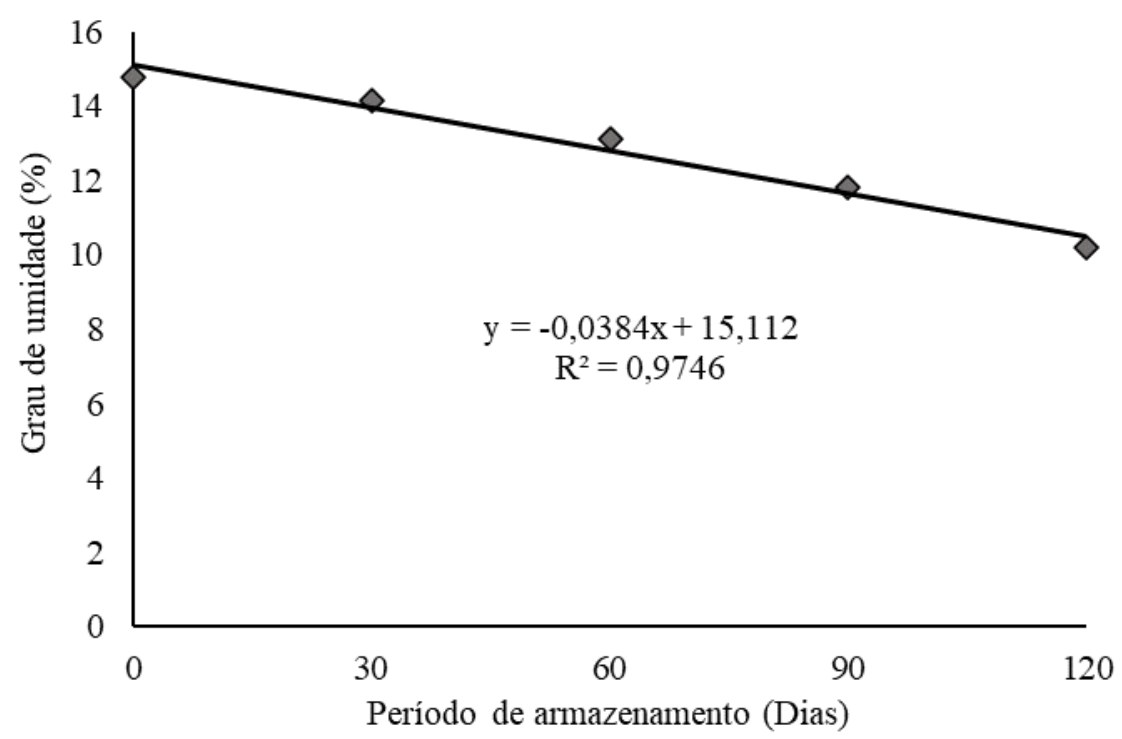

Fonte: Arquivo Pessoal (2022).

Os resultados obtidos para a condutividade elétrica das sementes também apresentaram um ajuste linear (Figura 2), mas com um padrão crescente com o aumento do tempo de armazenamento. A maior condutividade foi observada aos 120 dias, atingindo um resultado de $414,08 \mu \mathrm{S} \mathrm{cm}^{-1} \mathrm{~g}^{-1}$. Os resultados obtidos se mostraram superiores aos encontrados por Figueiredo Neto et al. (2012), que trabalhando com armazenamento de sementes de abóbora (Cucurbita maxima) armazenadas por 12 meses obtiveram-se um resultado máximo de $154,50 \mu \mathrm{S} \mathrm{cm}^{-1} \mathrm{~g}^{-1}$ de condutividade elétrica aos 90 dias. 
Figura 2. Condutividade elétrica de sementes de "Abóbora de Porco" sob diferentes períodos de armazenamento.

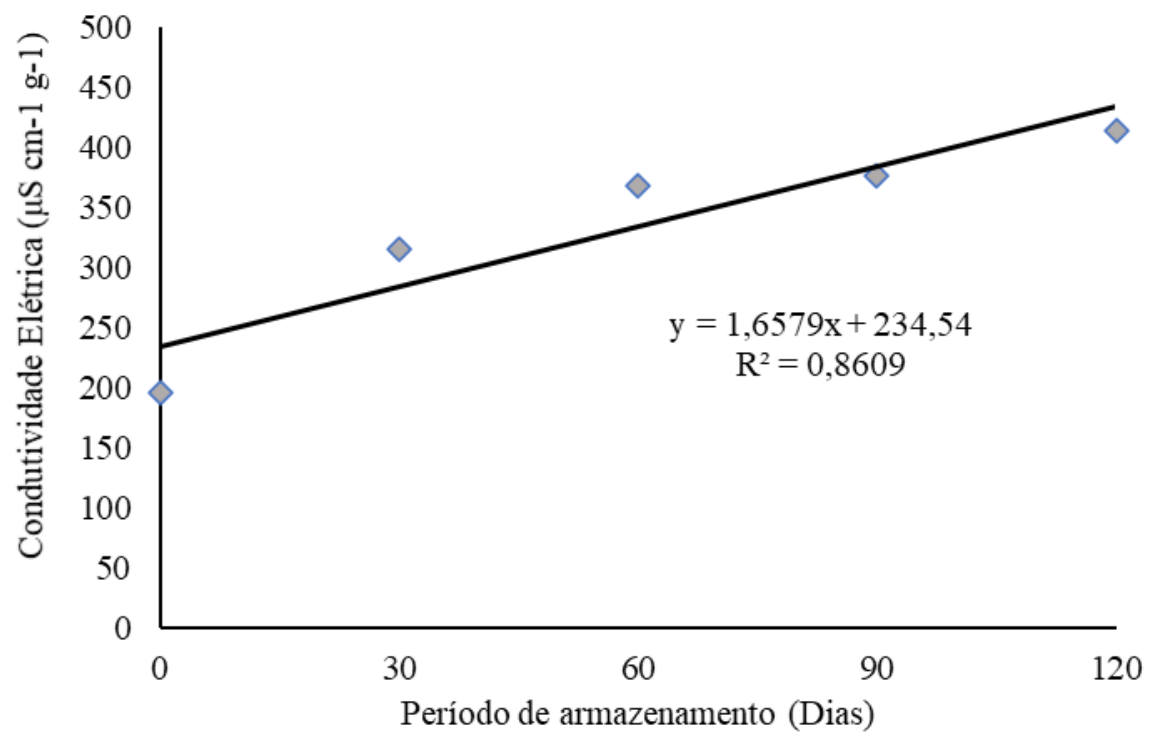

Fonte: Arquivo Pessoal (2022).

Esse aumento linear da condutividade elétrica das sementes denota o aumento na desorganização dos sistemas de membranas das células com o passar do tempo de armazenamento, por conta de processos degenerativos fisiológicos, fazendo com que ocorra maior liberação de lixiviados na solução (Abreu et al., 2011). A leitura da condutividade elétrica pode ser utilizada para avaliar o vigor, pois está relacionada com a quantidade de íons lixiviados na solução e a integridade das membranas celulares, sendo que membranas desestruturadas e danificadas, resultado do armazenamento incorreto, elevam o valor da condutividade elétrica e, em contrapartida, reduzem o vigor dos grãos e sementes (Faroni et al., 2005; Costa et al., 2010; Paraginski et al., 2015).

Não foram observadas diferenças significativas em relação à germinação das sementes em razão dos tratamentos aplicados (Tabela 2). A aplicação ou não do tratamento químico não influenciou na germinação das sementes, assim como os diferentes períodos de armazenamento, mantendo-se com no mínimo de 80\% de germinação. De acordo com Brasil (2019), as sementes comerciais de abóbora devem ter germinação mínima de $80 \%$ para sementes certificadas, dessa forma todos os tratamentos se adequaram a essa exigência.

Assim como na germinação, a massa seca das plântulas não apresentou diferenças estatísticas em nenhum dos tratamentos. A massa seca obtida a partir das plântulas provenientes do TG representa uma opção altamente viável para avaliação da qualidade fisiológica de sementes, já que sementes vigorosas tendem a apresentar plântulas melhores formadas e com maior massa, apresentando baixo custo, não necessitando de equipamentos especiais, além de não demandar treinamento adicional específico sobre a técnica empregada e são relativamente rápidos (Amaro et al.; 2015).

O teste de germinação é realizado sob condições favoráveis, que permitem que o lote de sementes expresse sua capacidade máxima. Dessa forma, quando as condições de campo são ótimas, o teste de germinação pode predizer corretamente o desempenho do lote em campo (Bertolin et al., 2011). Porém, na maioria dos casos isso não acontece. O resultado do teste de germinação superestima os valores reais da emergência de plantas em campo, estas deficiências levam a observação de que nem todas as facetas da qualidade das sementes são devidamente identificadas pelo teste de germinação (Bertolin et al., 2011). 
Tabela 2. Teste de Germinação (TG), Massa Seca de Plântulas do TG (MSG) e Emergência em campo (EC) de sementes de abóbora com e sem tratamento químico e sob armazenamento. Ceres, GO. 2021.

\begin{tabular}{|c|c|c|c|c|}
\hline & Tratamentos & TPG & MSPG & $\mathbf{E C}$ \\
\hline \multirow{2}{*}{0 dias } & Sem tratamento & $80 \mathrm{a}$ & $3,38 \mathrm{a}$ & $84 a$ \\
\hline & Com tratamento & $84 a$ & $3,94 \mathrm{a}$ & $83 a$ \\
\hline \multirow{2}{*}{30 dias } & Sem tratamento & $80 \mathrm{a}$ & $3,42 \mathrm{a}$ & $77 \mathrm{ab}$ \\
\hline & Com tratamento & $87 \mathrm{a}$ & $3,73 \mathrm{a}$ & $83 a$ \\
\hline \multirow{2}{*}{60 dias } & Sem tratamento & $89 a$ & $3,91 \mathrm{a}$ & $69 b$ \\
\hline & Com tratamento & $80 \mathrm{a}$ & $3,66 \mathrm{a}$ & $82 \mathrm{ab}$ \\
\hline \multirow{2}{*}{90 dias } & Sem tratamento & $88 \mathrm{a}$ & $3,81 \mathrm{a}$ & $70 \mathrm{ab}$ \\
\hline & Com tratamento & $86 a$ & $4,02 \mathrm{a}$ & $81 \mathrm{ab}$ \\
\hline \multirow{2}{*}{120 dias } & Sem tratamento & $88 \mathrm{a}$ & $3,85 \mathrm{a}$ & $57 \mathrm{c}$ \\
\hline & Com tratamento & $81 \mathrm{a}$ & $3,62 \mathrm{a}$ & $59 c$ \\
\hline & $\mathrm{CV}(\%)$ & 7,4 & 11,9 & 14,0 \\
\hline
\end{tabular}

Médias seguidas por letras distintas na coluna diferem entre si. CV (\%) - Coeficiente de variação.

Fonte: Arquivo Pessoal (2022).

Para análise mais precisa da qualidade de sementes, faz-se necessário complementar as informações fornecidas pelo teste de germinação com testes de vigor, possibilitando, assim, selecionar os melhores lotes para comercialização e semeadura (Araújo et al., 2011).

O teste de emergência em campo apresentou resultados diferentes quanto aos obtidos no teste de germinação (Tabela 2). As sementes tratadas e não tratadas quimicamente apresentaram os menores resultados e foram diferentes estatisticamente dos demais para emergência de plântulas no período de 120 dias. Isso mostra que o tratamento de sementes tem uma maior eficiência quando aplicado de forma imediata antes da semeadura. Almeida et al. (2020) constataram que com a aplicação de Standak ${ }^{\circledR}$ Top em sementes de abóbora BRS Brasileirinha, foi possível obter resultados de $94 \%$ de emergência aos 14 dias em campo. No presente trabalho foi obtido resultado de emergência de $83 \%$ no dia zero, sem passar por armazenamento. Esses resultados da emergência em campo correspondem aos observados na análise da condutividade elétrica (Figura 2), onde houve um decréscimo na emergência nos diferentes períodos de armazenamento, enquanto a condutividade elétrica teve um aumento. O teste de emergência de plântulas em campo constitui parâmetro indicador da eficiência dos testes para avaliação do potencial fisiológico de lotes de sementes, apresentando uma alternativa que melhor simula as condições naturais para formação de um estande de plantas (Torres et al., 2014).

Por outro lado, quando realizada a análise de regressão da emergência de plântulas em campo, a aplicação do tratamento químico apresentou comportamento diferente com o não aplicado (Figura 3). As sementes sem aplicação do tratamento químico apresentaram um ajuste linear negativo, com o decréscimo da emergência ao decorrer dos períodos estabelecidos. As sementes com aplicação do tratamento químico apresentaram um ajuste quadrático, em que até os 90 dias de armazenamento as plantas apresentaram $81 \%$ de emergência, ocorrendo uma diminuição aos 120 dias, atingindo $59 \%$. 
Figura 3. Emergência em campo de sementes de "Abóbora de Porco" com e sem tratamento químico e sob diferentes períodos de armazenamento.

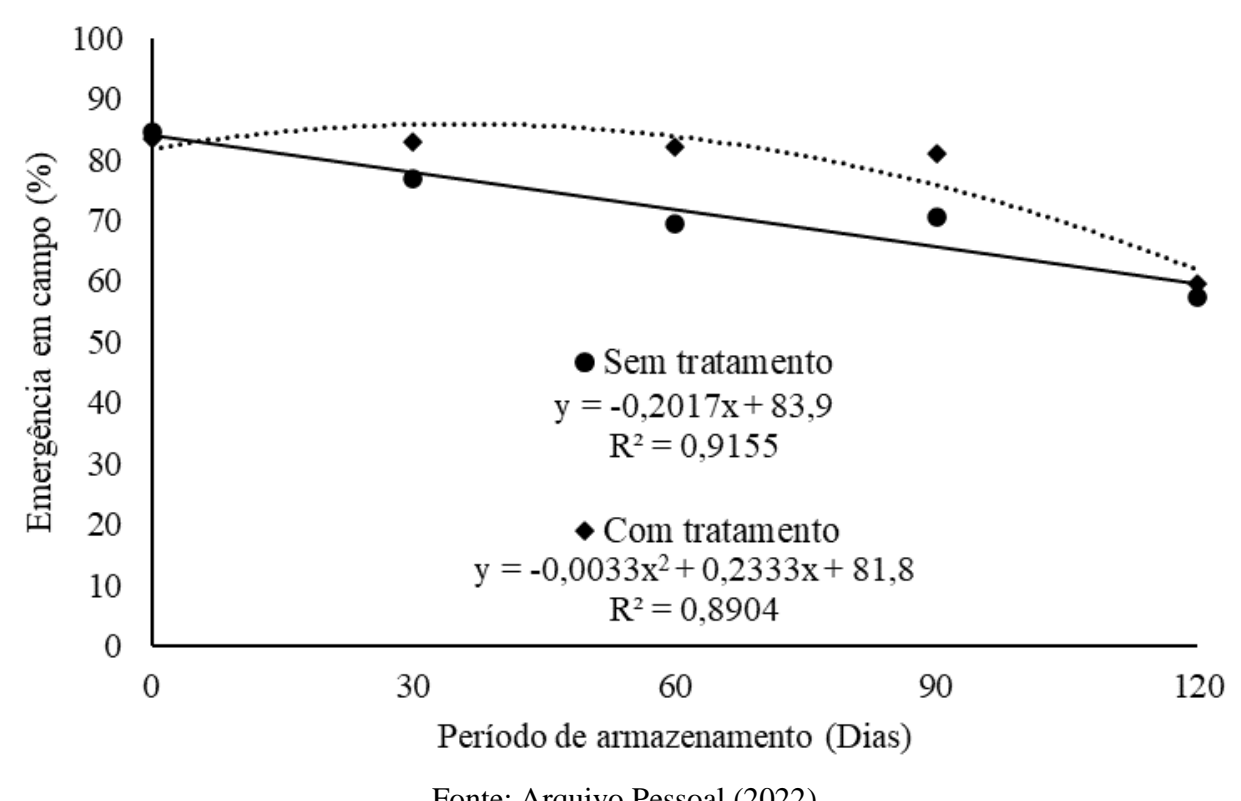

Fonte: Arquivo Pessoal (2022).

Esses resultados evidenciam a eficiência do tratamento químico que promoveu maior emergência das sementes armazenadas até um período de 90 dias. As sementes não tratadas apresentaram resultados menores a partir de 60 dias de armazenamento. A alta incidência de insetos e patógenos, principalmente de fungos, associados às sementes causa danos consideráveis, especialmente em cucurbitáceas ocasionando perdas de plantas no estande e até mesmo perdas totais da produção (Soares et al., 2016). O tratamento de sementes de abóbora não melhora a qualidade das sementes, mas pode ajudar na manutenção de melhores resultados quando são realizados os testes de vigor.

Em relação a análise de regressão do IVE, pode-se observar que tanto as sementes tratadas e as não tratadas com fungicidas apresentaram um ajuste quadrático (Figura 4). Os menores resultados foram observados aos 60 dias para as sementes sem tratamento $(4,90)$ e com tratamento $(5,26)$. Após esse período de armazenamento as sementes aumentaram o IVE até aos 120 dias. Esses resultados inferiores do índice de velocidade de emergência no período de 30 a 60 dias, podem ser explicados principalmente pelo frio que ocorreu no período do experimento nos meses de julho e agosto. 
Figura 4. Índice de velocidade de emergência em campo de sementes de "Abóbora de Porco" com e sem tratamento químico e sob diferentes períodos de armazenamento.

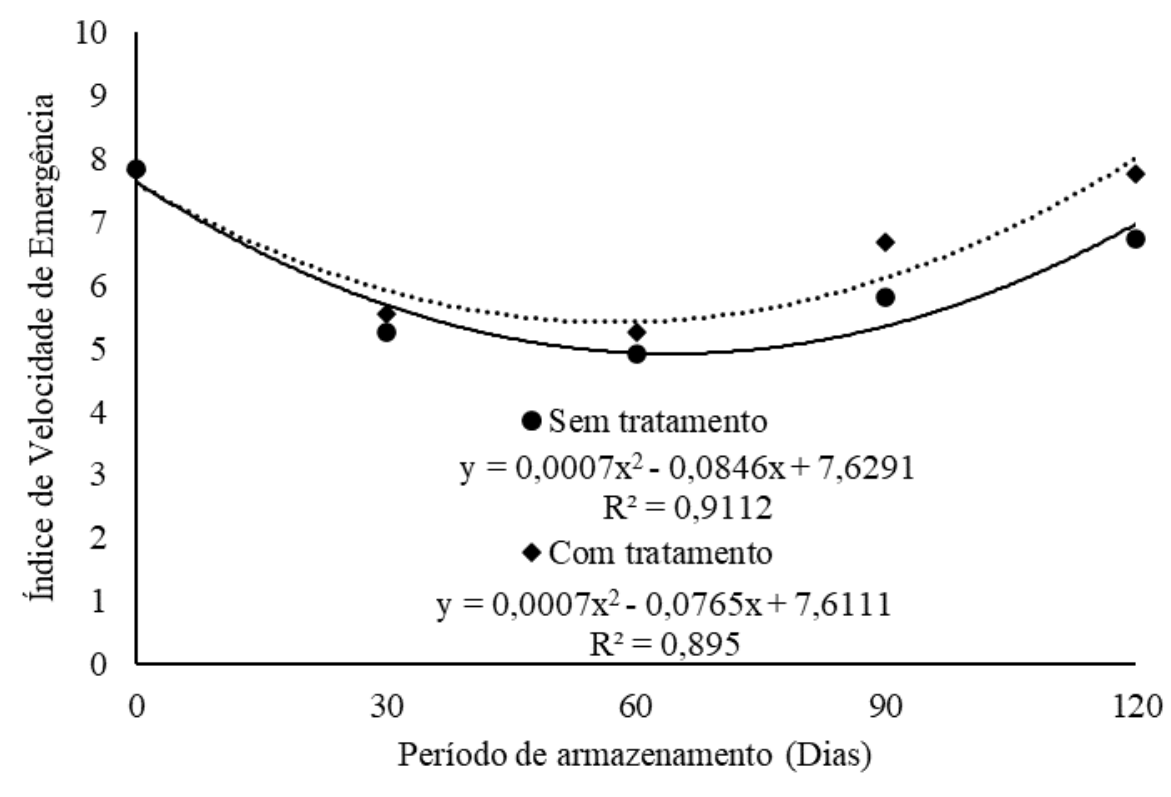

Fonte: Arquivo Pessoal (2022).

Segundo dados da estação meteorológica do IF Goiano - Campus Ceres, no mês de julho a média diária foi de $13{ }^{\circ} \mathrm{C}$ para temperaturas mínimas e máximas de $31{ }^{\circ} \mathrm{C}$, enquanto no mês de agosto foram observadas médias de até $14{ }^{\circ} \mathrm{C}$ de temperatura mínima e máximas de $31^{\circ} \mathrm{C}$. Para efeitos de comparação no mês de junho as temperaturas diárias médias foram de $18{ }^{\circ} \mathrm{C}$ para mínimas e $33^{\circ} \mathrm{C}$ para máximas, enquanto o mês de outubro apresentou $21^{\circ} \mathrm{C}$ para mínimas e $33{ }^{\circ} \mathrm{C}$ para máximas, sendo esses os meses em que foram obtidos os maiores resultados para o índice de velocidade de emergência. A cultura da abóbora tolera melhores condições de temperaturas elevadas e possui menor tolerância ao estresse pelo frio, que prejudica a germinação e emergência de plântulas, levando a problemas na formação do estande de plantas por falta de homogeneidade e menor número de plantas (Boligon et al., 2010).

Conforme Campos et al. (2015), o vigor do lote de sementes é determinado no teste do índice de velocidade de emergência, avaliando a velocidade de emergência de plântulas em condições de campo e/ou em casa de vegetação. Dessa forma, sementes de alto vigor conseguem mobilizar com maior rapidez suas reservas energéticas, proporcionando maior crescimento inicial e desenvolvimento.

\section{Considerações Finais}

Não houve diferença na germinação de sementes de abóbora de porco com a aplicação ou não de tratamento químico nos diferentes períodos de armazenamento.

As sementes armazenadas perderam umidade e tiveram aumento da condutividade elétrica com o aumento do período de armazenamento.

A emergência em campo de sementes de abóbora de porco com tratamento químico foi maior até aos 90 dias.

\section{Referências}

Abreu, L. A. S., Carvalho, M. L. M., Pinto, C. A. G. \& Kataoka, V. Y. (2011) Teste de condutividade elétrica na avaliação de sementes de girassol armazenadas sob diferentes temperaturas. Revista Brasileira de Sementes, 33 (4), 635-642. 
Almeida, A. S., Suñe, A. S., Nunes, C. Á., Melo, A. J., Moura, D. S., Mambrin, R., Otalakoski, J. \&Munari, J. (2020). Desempenho dos substratos utilizados para o teste de germinação com sementes de abobora BRS Brasileirinha tratadas. Brazilian Journal of Development, 6 (12), 98197-98205.

Amaro, H. T. R., David, A. M. S. S., Assis, M. O., Rodrigues, B. R. A., Cagussu, L. V. S. \& Oliveira, M. B. (2015). Testes de vigor para avaliação da qualidade fisiológica de sementes de feijoeiro. Ciências Agrárias, 38 (3), 383-389.

Andrade, E. T., Corrêa, P. C., Martins, J. H. \& Alvarenga, E. M. (1999). Avaliação de dano mecânico em sementes de feijão por meio de condutividade elétrica. Revista Brasileira de Engenharia Agrícola e Ambiental-Agriambi, 3 (1), 54-60.

Araújo, R. F., Zonta, J. B., Araujo, E. F., Heberle, E. \& Zonta F. M. G. (2011). Teste de condutividade elétrica para sementes de feijão-mungo-verde. Revista Brasileira de Sementes, 33 (1), 123-130.

Bertolin, D. C, Sá, M. E. \& Moreira, E. R. (2011). Parâmetros do teste de envelhecimento acelerado para determinação do vigor de sementes de feijão. Revista Brasileira de Sementes, 33 (1), 104-112.

Boligon, A. A., Lúcio, A. D. C. \& Garcia, D. C. (2010). Emergência de plântulas de abóbora a partir da avaliação da qualidade das sementes. Ciência Rural, 40 (11), 2274-2281.

Brasil. Ministério da Agricultura, Pecuária e Abastecimento. (2009). Regras para análise de sementes/Ministério da Agricultura, Pecuária e Abastecimento. Secretaria de Defesa Agropecuária. - Brasília: Mapa/ ACS. 399 p.

Brasil. Ministério da Agricultura, Pecuária e Abastecimento. (2019). Instrução normativa $n^{\circ} 42$, de 17 de setembro de 2019. Diário Oficial da União, $\mathrm{n}^{\circ}$ 182, quinta-feira, 19 de set. de 2019.

Campos, L. F. C., Abreu, C. M., Guimarães, R. N. \& Seleguini, A. (2015). Escarificação e ácido giberélico na emergência e crescimento de plântulas de biribá. Ciência Rural, 45 (10), 1748-1754.

Cardoso, A. I. I. (2005). Polinização manual em abobrinha: efeitos nas produções de frutos e de sementes. Horticultura Brasileira, 23 (3), $731-734$.

Carvalho, N. M. \& Nakagawa, J. (2012). Sementes: ciência, tecnologia e produção. 5 ed. Jaboticabal: Funep. 590 p.

Coelho, V. A. T., Souza, C. G., Nascimento, E. S., Lacerda, L. G. \& Cardoso, P. A. (2020). Deficiências de macronutrientes em abobrinha italiana (Cucurbita pepo L.): caracterização de sintomas e crescimento. Research, Society and Development, 9 (3), 1-19.

Costa Júnior, J. R., Oliveira, D. E. C., Carvalho, J. M. G., Bueno, Sarah G. S., Ferreira, V. B. \& Alves, E. M. (2021). Forma e tamanho de sementes de duas variedades de abóboras durante a secagem. Nativa, 9 (1), 01-08.

Costa, A. R., Faroni, L. R. D., Alencar, E. R., Carvalho, M. C. S. \& Ferreira, L. G. (2010). Qualidade de grãos de milho armazenados em silos bolsa. Revista Ciência Agronômica, 41 (1), 200-207.

CPRA - Centro Paranaense de Referência em Agroecologia. (2021). “Abóbora”. Disponível em: http://www.cpra.pr.gov.br/arquivos/File/Abobora.pdf. 2014. Acesso em: 20 de maio de 2021.

Faroni, L. R. A., Barbosa, G. N. O., Sartori, M. A., Cardoso, F. S. \& Alencar, E. R. (2005). Avaliação qualitativa e quantitativa do milho em diferentes condições de armazenamento. Engenharia na Agricultura, 13 (3), 193-201.

Figueiredo Neto, A., Lima, M.S., Silva, M.F., Dantas, B.F. \&Teixeira, R.A. (2012). Armazenamento e qualidade fisiológica de sementes de abóbora. Revista Brasileira de Agropecuária Sustentável, 2 (2), 44-50.

Freitas, M. C. M. (2011). A cultura da soja no Brasil: o crescimento da produção brasileira e o surgimento de uma nova fronteira agrícola. Enciclopédia Biosfera, 7 (12), 1-12.

Freitas, P. G. N., Claudio, M. T. R., Tavares, A. E. B., Magro, F. O., Cardoso, A. I. I. \& Bardiviesso, E. M. (2014). Poda apical para produção de frutos e sementes de abóbora. Revista Agro@mbiente On-line, 8 (2), 230-237.

Goldfarb, M. \& Queiroga, V. P. (2013). Considerações sobre o armazenamento de sementes. Tecnologia e Ciência Agropecuária, 7 (3), $71-74$.

Gomes Junior, F. G. \& Sá, M. E. (2010). Proteína e qualidade de sementes de feijão (Phaseolus vulgaris L.) em função da adubação nitrogenada em plantio direto. Revista Brasileira de Sementes, 32 (1), 34-44.

Maciel, G. M., Carvalho, F. J., Fernandes, M. A. R., Beloti, I. F. \& Oliveira, C.S. (2015). Efeitos genéticos, ambientais e período de armazenamento na qualidade de sementes de cebola. Bioscience Journal, 31 (6), 1634-1642.

Maguire, J. D. (1962). Speed of germination-aid in selection and evaluation for seedling emergence and vigor. Crop Science, 2,176-177.

Marcos Filho, J. (2015). Fisiologia de sementes de plantas cultivadas. Londrina: ABRATES. 660p.

Medeiros, L. T., Sales, J. F., Souza, R. G., Alves, B. A. \& Freitas, N. F. (2013). Qualidade fisiológica de sementes de amendoim forrageiro submetidas a diferentes tempos e ambientes de armazenamento. Revista Brasileira de Saúde e Produção Animal, 14 (3), 472-477.

Melo, D., Brandão, W. T. M., Nóbrega, L. H. P. \& Werncke, I. (2016). Qualidade de sementes de soja convencional e Roundup Ready (RR), produzida para consumo próprio e comercial. Revista de Ciências Agrárias, 39(2), 300-309.

Nascimento, W. M., Freitas, R. A. \& Croda, M. D. (2008). Conservação de sementes de hortaliças na agricultura familiar. Brasília: Comunicado Técnico 54, $1-5$.

Nunes, J. C. S. (2016). Tratamento de sementes de soja como um processo industrial no Brasil. Revista SEED News, 20 (1), 26-32. 
Research, Society and Development, v. 11, n. 2, e48311226024, 2022

(CC BY 4.0) | ISSN 2525-3409 | DOI: http://dx.doi.org/10.33448/rsd-v11i2.26024

Paraginski, R. T., Rockenbach, B. A., Santos, R. F. dos, Elias, M. C. \& Oliveira, M. (2015). Qualidade de grãos de milho armazenados em diferentes temperaturas. Revista Brasileira de Engenharia Agrícola e Ambiental, 19 (4), 358-363.

Queiroga, V. P., Castro, L. B. Q., Gomes, J. P., Jerônimo, J. F. \& Pedroza, J. P. (2009). Qualidade de sementes de algodão armazenadas em função de diferentes cultivares e teores de água. Revista Caatinga, 22 (4), 136-144.

Sales, M. A. L., Moreira, F. J. C., Ribeiro, A. A., Monteiro, R. N. F. \& Sales, F. A. L. (2015). Potencial das sementes de abóbora submetidas a diferentes períodos de embebição. Revista Brasileira de Engenharia de Biossistemas, 9 (4), 289-297.

Silva, J. S., Afonso, A. D. L. \& Lacerda Filho, A. F. (1995) Secagem e armazenagem de produtos agrícolas. In: Silva, J. S. Pré-processamento de produtos agrícolas. Juiz de Fora: Instituto Maria, 395-462.

Silva, S. N. \& Lopes, J. C. (2012). Qualidade física e fisiológica de sementes de abóbora variedade Jacarezinho. Enciclopédia Biosfera, 8 (15), 1490-1499.

Soares, M. G. O., Soares, J. A., Cezar, M. A., Cardoso, T. A. L. \& Lima, J. A. A. (2016). Ocorrência de patógenos em cultivos de melancia e abóbora no sertão da Paraíba. Revista Verde de Agroecologia e Desenvolvimento Sustentável, 11, 07-13.

Tonin, R.B., Lucca Filho, O. A., Labbe, M. L. B. \& Rossetto, M. (2014). Potencial fisiológico de sementes de milho híbrido tratadas com inseticidas e armazenadas em duas condições de ambiente. Scientia Agropecuaria, 5 (1), 07-16.

Torres, S. B., Silva, F. G., Gomes, M. D. A., Benedito, C. P., Pereira, F. E. C. B. \& Silva, E. C. (2014). Diferenciação de lotes de sementes de quiabo pelo teste de envelhecimento acelerado. Ciência Rural, 44 (12), 2103-2110.

Wagner Júnior, A., Silva, J. O. C, Pimentel, L. D., Santos, C. E. M. \& Bruckner, C. H. (2011). Germinação e desenvolvimento inicial de duas espécies de jabuticabeira em função do tamanho de sementes. Acta Scientiarum Agronomy, 33 (1), 105-109.

Zucareli, C., Brzezinski, C. R., Abati, J., Werner, F., Ramos, E. U. \& Nakagawa, J. (2015). Qualidade fisiológica de sementes de feijão carioca armazenadas em diferentes ambientes. Revista Brasileira de Engenharia Agrícola e Ambiental, 19 (8), 803-809. 